\title{
ANALISIS PROGRAM KEGIATAN USAHA KESEHATAN GIGI SEKOLAH (UKGS) DI PUSKESMAS HALMAHERA
}

\author{
Rieza Zulfahmi Taftazani $^{1}$, Lina Rismayani ${ }^{2}$, Bedjo Santoso ${ }^{\varpi^{3}}$, Tri Wiyatini ${ }^{4}$
}

\begin{abstract}
ABSTRAK
Puskesmas Halmahera merupakan salah satu Puskesmas di Kota Semarang yang menjalankan program UKGS tahap II pada 14 sekolah dasar (SD) dan tahap III pada 1 SD. Kegiatan UKGS di Puskesmas Halmahera meliputi penyuluhan, sikat gigi masal dan penjaringan kesehatan gigi dan mulut yang dilaksanakan hanya satu tahun sekali, yang pada akhirnya berdampak pada tidak tercapainya program UKGS yang ditargetkan kementerian Kesehatan. Pemerintah mentargetkan kondisi kesehatan gigi dan mulut pada tahun 2014 seperti prevalensi bebas karies pada molar satu (M1) sebanyak 50\%, penyuluhan dilaksanakan satu kali pertriwulan $80 \%$ SD dan kegiatan sikat gigi bersama dilaksanakan setiap hari di sekolah di 50\% SD. Berdasarkan data tersebut, terjadi kesenjangan antara keadaan kesehatan gigi dan mulut murid SD di wilayah Puskesmas Halmahera Semarang terhadap target pemerintah. Tujuan penulisan laporan kasus ini untuk menganalisis permasalahan program UKGS di Puskesmas Halmahera.

Laporan kasus ini disusun menggunakan metode observasional melalui pengamatan data, task analysisdengan pengamatan terhadap pekerjaan yang dilakukan tenaga kesehatan gigi yang berhubungan dengan kegiatan UKGS, wawancara guna menggali informasi terhadap pelaksanaan program kepada penanggungjawab kegiatan UKGS di Puskesmas Halmahera Semarang. Hasil kegiatan tersebut didapatkan prioritas masalah dalam UKGS yang belum optimal sesuai dengan pedoman UKGS 2012, dikarenakan kurangnya tenaga kesehatan gigi dan mulut khususnya perawat gigi yang merupakan ujung tombak pelaksana UKGS. Hal tersebut sesuai dengan Peraturan Menteri Kesehatan Nomor 58 Tahun 2012 bahwa perawat gigi berwenang melakukan kegiatan promotif dan preventif termasuk melakukan kegiatan UKGS. Tidak ada dana operasional kegiatan UKGS dari Dinas Kesehatan Kota Semarang, sehingga kegiatan tersebut sulit untuk dilakukan, monitoring dan evalusi kegiatan UKGS tidak dilakukan, kurangnya partisipan orang tua dan motivasi anak dalam perawatan kesehatan gigi dan mulut lanjutan.

Laporan kasus ini dapat disimpulkan bahwa tidak berhasilnya kegiatan UKGS di Puskesmas Halmahera Semarang dipengaruhi oleh kurangnya tenaga kesehatan gigi, tidak ada dana operasional kegiatan UKGS, tidak adanya monitoring dan evaluasi, dan kurangnya partisipasi dan motivasi orang tua terhadap perawatan gigi lanjutan.
\end{abstract}

Kata kunci : Pelayanan Kesehatan Gigi dan Mulut, UKGS, Puskesmas.

\begin{abstract}
Public Health Center Halmahera is one of the health centers in the city of Semarang which runs UKGS phase II program in 14 elementary school (SD) and stage III at 1 SD. UKGS in Halmahera PHC activities include counseling, mass and networking toothbrush oral health carried out only once a year, which in turn have an impact on not achieving a targeted program UKGS Ministry of Health. The government is targeting oral health conditions in 2014 as the prevalence of caries-free in one molar (M1) by 50\%, the extension executed onece each quaertermester $80 \%$ SD and activities jointly undertaken toothbrush every day at school in 50\% SD. Based on these data, there is a gap between the state of oral health of elementary school students in the area of PHC Halmahera Semarang against government targets. The purpose of writing this case report to analyze the problems in the health center program UKGS Halmahera.

This case report was compiled using the observational method through observation of data, task analysis with the observation of the work performed by dental health workers related to UKGS activities, interviews to gather information on the implementation of the program to UKGS activities manager's in Puskesmas Halmahera Semarang.The activity results obtained in UKGS priority issues that have not been optimized in accordance with the guidelines UKGS 2012, due to lack of dental care, especially dental nurse who is spearheading the implementing UKGS.This is in accordance with the Regulation of the Minister of Health No. 58 of 2012 that the dental nurse is authorized to conduct promotive and preventive activities including conducting UKGS.There is no UKGS operational funds from Semarang City Health Office, so that the activity is difficult to do, UKGS monitoring and evaluation activities cannot be conducted, lack of parents participants's role and children's motivation in dental and follow-through oral health care.

The report in this case conclude that UKGS activity is unsuccessful in Halmahera Semarang Public health center affected by the lack of dental health workers, there are no UKGS operational funds, the absence of monitoring and evaluation, and the lack of participation and motivation of parents toward advanced dental care.
\end{abstract}

Keywords: Dental and Oral Health Care, UKGS, Public Health Center.

\footnotetext{
1,2) Mahasiswa Pascasarjana Science Terapan Epidemiologi UNDIP

${ }^{3,4)}$ Dosen Jurusan Keperawatan Gigi Poltekkes Kemenkes Semarang

$\bowtie$ : bedjosantoso27@gmail.com
} 


\section{PENDAHULUAN}

Kesehatan gigi dan mulut masyarakat Indonesia masih perlu mendapat perhatian serius dari tenaga kesehatan baik dokter maupun perawat gigi sebagaimana hasil Riset Kesehatan Dasar Nasional (Riskesdas) tahun 2013 menyebutkan bahwa prevalensi nasional masalah gigi dan mulut adalah $25,9 \%$, sebanyak 14 provinsi mempunyai prevalensi masalah gigi dan mulut diatas angka nasional. Penyakit gigi dan mulut menduduki urutan pertama dari daftar 10 besar penyakit yang paling sering dikeluhkanmasyarakat Indonesia. Persepsi dan perilaku masyarakat Indonesia terhadap kesehatan gigi dan mulut masih buruk. Ini terlihat dari masih besarnya angka karies gigi dan penyakit mulut di Indonesia yang cenderung meningkat (Riskesdas, 2013).

Hasil studi morbiditas SKRT (Survey Kesehatan Rumah Tangga) - Surkenas (Survey Kesehatan Nasional) 2001 menunjukkan bahwa secara umum antara penyakit yang dikeluhkan dan tidak dikeluhkan, prevalensi penyakit gigi dan mulut adalah yang tertinggi meliputi $60 \%$ penduduk. Sedangkan pada golongan umur 5-14 tahun prevalensi penyakit gigi dan mulut adalah 33\% dan meningkat dengan bertambahnya umur (SKRT, 2001).

Anak-anak lebih rentan mengalami masalah kesehatan gigi dan mulut. Masa kanak-kanak pertengahan 6-12 tahun sering disebut sebagai masa-masa yang rawan, karena pada masa itulah gigi susu mulai tanggal satu persatu dan gigi permanen pertama mulai tumbuh (usia 6-8 tahun). Dengan adanya variasi gigi susu dan gigi permanen bersama-sama di dalam mulut, menandai masa gigi campuran pada anak. Gigi yang baru tumbuh tersebut belum matang sehingga rentan terhadap kerusakan (Riyanti, 2012). Oleh karena itu, gigi permanen yang tumbuh hanya satu kali dalam seumur hidup harus dijaga, dirawat dan dipelihara dengan baik supaya terhindar dari masalah gigi.Menjaga kebersihan gigi harus dilakukan setiap hari sehingga gigi dan mulut bersih dari sisa-sisa makanan yang bisa menyebabkan kerusakan gigi. Kerusakan gigi pada anak bisa menyebabkan gangguan masalah pertumbuhan dan perkembangan pada anak akibat kekurangan gizi. Rasa sakit pada gigi dan mulut akan menurunkan selera makan anak dan pemecahan makanan di dalam mulut tidak sempurna sehingga penyerapan nutrisi yang dibutuhkan oleh tubuh akan terganggu (Cahyati, W.H. 2008).

Masalah utama dalam rongga mulut anak adalah karies gigi. Prevalensi karies gigi di negara-negara maju terus menurun sedangkan di negara-negara berkembang termasuk Indonesia cenderung meningkat. Organisasi Kesehatan Dunia (WHO) tahun 2003 menyatakan, angka kejadian karies pada anak usia Sekolah Dasar 60-90\%. Prevalensi akan terus meningkat seiring bertambahnya umur (Adiwiryono, 2011).

Data terbaru yang dirilis oleh Oral Health Media Centre pada April 2012, memperlihatkan sebanyak 60-90\% anak usia sekolah dan hampir semua orang dewasa di seluruh dunia memiliki permasalahan gigi.Anak usia 6 tahun telah mengalami karies pada gigi tetapnya sebanyak $20 \%$, meningkat $60 \%$ pada usia 8 tahun, $85 \%$ pada 10 tahun dan $90 \%$ pada usia 12 tahun (Novita, 2008).

Prevalensi karies pada kelompok anak usia 12 tahun cenderung meningkat dari 62,64\% pada tahun 2007 menjadi 72,86\% pada tahun 2013 (Riskesdas, 2013). Hasil Riskesdas 2007 memperlihatkan bahwa indeks DMF-T pada umur 12 tahun ke atas sebesar 0,91 yang berarti bahwa jumlah kerusakan gigi rata-rata 91 kerusakan gigi per 100 orang. Terjadi peningkatan indeks DMF-T pada tahun 2013 yaitu menjadi 1,4 yang berarti bahwa jumlah kerusakan gigi rata-rata menjadi 140 kerusakan gigi per 100 orang. Angka tersebut tentu saja sangat jauh bila dibandingkan dengan program WHO yang mencanangkan sampai 2020 nilai DMF-T anak-anak adalah 1 (Prihastari, L. 2014). 
Berdasarkan data-data diatas sebaiknya dilakukan upaya pemeliharaan kesehatan gigi dan mulut sejak usia dini. Peran sekolah sangat diperlukan dalam proses menciptakan kebiasaan menyikat gigi pada anak. Usia sekolah dasar merupakan saat ideal untuk melatih kemampuan motorik seorang anak, termasuk menyikat gigi (Riyanti, 2012).

Departemen Kesehatan telah memprogramkan upaya promotif dan preventif untuk anak usia sekolah melalui Usaha Kesehatan Gigi Sekolah (UKGS). Upaya promotif dan preventif paling efektif dilakukan dengan sasaran anak sekolah dasar, karena perawatan kesehatan gigi harus dilakukan sejak dini dan dilakukan secara kontinyu agar menjadi suatu kebiasaan. Usaha Kesehatan Gigi Sekolah (UKGS) adalah salah satu usaha pokok Puskesmas yang termasuk dalam Usaha Kesehatan Sekolah (UKS). Termasuk di dalam program UKGS adalah pelaksanaan pelayanan kesehatan gigi dan mulut pada murid-murid sekolah dasar, yaitu meliputi dental health education dan pemeriksaan gigi dan mulut (Darwita, 2006).

Puskesmas Halmahera merupakan salah satu Puskesmas di Kota Semarang yang menjalankan program UKGS tahap II pada 14 sekolah dasar (SD) dan tahap III pada 1 SD. Kegiatan UKGS di Puskesmas Halmahera meliputi penyuluhan, sikat gigi masal dan penjaringan kesehatan gigi dan mulut yang dilaksanakan hanya satu tahun sekali, yang pada akhirnya berdampak pada tidak tercapainya program UKGS yang ditargetkan kementerian Kesehatan. Pemerintah mentargetkan kondisi kesehatan gigi dan mulut pada tahun 2014 seperti prevalensi bebas karies pada molar satu (M1) sebanyak $50 \%$, penyuluhan dilaksanakan satu kali pertriwulan $80 \%$ SD dan kegiatan sikat gigi bersama dilaksanakan setiap hari di sekolah di 50\% SD. Berdasarkan data tersebut, terjadi kesenjangan antara keadaan kesehatan gigi dan mulut murid SD di wilayah Puskesmas Halmahera Semarang terhadap target pemerintah. Tujuan penulisan laporan kasus ini untuk menganalisis permasalahan program UKGS di Puskesmas Halmahera.

\section{METODE PENELITIAN}

Laporan kasus ini disusun menggunakan metode observasional melalui pengamatan data, task analysis dengan pengamatan terhadap pekerjaan yang dilakukan tenaga kesehatan gigi yang berhubungan dengan kegiatan UKGS, wawancara guna menggali informasi terhadap pelaksanaan program kepada penanggungjawab kegiatan UKGS di Puskesmas Halmahera Semarang. Hasil observasi, task analysis dan wawancara tersebut diidentifikasi, ditentukan prioritas masalah dengan metode Briyant, kemudian dianalisa faktor-faktor penyebab dari masalah utama dengan menggunakan metode 6M : Man (sumber daya manusia),Money (anggaran dana), Material (sarana),Machine (prasarana), Method (metode/cara) dan Market (lingkungan).

\section{HASIL DAN PEMBAHASAN}

\section{Data hasil observasi kegiatan UKGS}

UKGS Tahap II, tahun 2013 dilaksanakan di 15 SD. Jumlahmurid yang diperiksa 743 anak dengan 222 anak dirawat dan dirujuk. Tahun 2014 dan 2015 dilaksanakan di 14 SD. Jumlah murid yang diperiksa 736 dan 667 anak dengan 173 dan 132 anak dirawat dan dirujuk.

UKGS Tahap III dilaksanakan di 1 SD pilihan yaitu SD Karang Tempel pada kelas III dan V. Jumlah murid yang diperiksa dan dilakukan perawatan tahun 2013 yaitu sebanyak 22 dan 32 anak. Tahun 2014 yang diperiksa dan dilakukan perawatan sebanyak 4 dan 12 anak. Tahun 2015 yang diperiksa dan dilakukan perawatan sebanyak 20 dan 19 anak. Untuk lebih jelasnya bisa dilihat pada tabel 1 dibawah ini. 
Tabel 1. UKGS di Wilayah Puskesmas Halmahera

\begin{tabular}{|c|c|c|c|c|}
\hline & UKGS & 2013 & 2014 & 2015 \\
\hline \multirow[t]{3}{*}{$\begin{array}{l}\text { Tahap } \\
\text { II }\end{array}$} & Jumlah SD & 15 & 14 & 14 \\
\hline & $\begin{array}{l}\text { Jumlah } \begin{array}{c}\text { Murid } \\
\text { yang diperiksa }\end{array} \\
\end{array}$ & 743 & 736 & 667 \\
\hline & $\begin{array}{l}\text { Jumlah Murid } \\
\text { yang dirawat \& } \\
\text { dirujuk }\end{array}$ & 222 & 173 & 132 \\
\hline \multirow[t]{5}{*}{$\begin{array}{l}\text { Tahap } \\
\text { III } \\
\end{array}$} & $\begin{array}{ll}\text { Jumlah } & \text { SD } \\
\text { Selektif } & \\
\end{array}$ & 1 & 1 & 1 \\
\hline & $\begin{array}{lc}\text { Jumlah } & \text { Murid } \\
\text { Selektif } & \text { Kelas III } \\
\end{array}$ & 22 & 4 & 20 \\
\hline & $\begin{array}{l}\text { Jumlah Murid } \\
\text { Selesai Perawatan } \\
\text { Kelas III }\end{array}$ & 22 & 4 & 20 \\
\hline & $\begin{array}{l}\text { Jumlah Murid } \\
\text { Selektif Kelas V }\end{array}$ & 32 & 12 & 19 \\
\hline & $\begin{array}{l}\text { Jumlah Murid } \\
\text { Selesai Perawatan } \\
\text { Kelas V }\end{array}$ & 32 & 12 & 19 \\
\hline
\end{tabular}

Hasil dari pemeriksaan kesehatan gigi dan mulut kelas III dan V tahun 2012 dan 2013 yang memerlukan perawatan sebanyak 8 dan 15 anak. Tahun 2014 sebanyak 16 dan 8 anak.

Jumlah persentase anak yang mengalami karies tahun 2013 kelas III dan V sebanyak 36\% dan 66\%. Tahun 2014 sebanyak $46 \%$ dan $66 \%$, dari data tersebut terjadi peningkatan persentase anak yang mengalami karies. Terlihat jelas pada grafik dibawah ini.

\section{Identifikasi Masalah}

Berdasarkan hasil observasi data, task analysis dan wawancara dengan penanggungjawab UKGS di Puskesmas Halmahera didapatkan beberapa masalah sebagai berikut:

Tabel 2. Identifikasi Masalah

\begin{tabular}{|c|c|c|c|c|}
\hline What & Where & When & Who & Why \\
\hline Pelaksanaan & di SD wilayah & Teridentifikasi & Murid SD & Kurangnya \\
\hline kegiatan & kerja & oleh Peneliti & wilayah & tenaga \\
\hline UKGS belum & Puskesmas & selama & Kerja & kesehatan \\
\hline optimal sesuai & Halmahera & melakukan & Puskesmas & gigi \\
\hline dengan & & kegiatan PBL & Halmahera & mulut, \\
\hline pedoman & & & & adanya dana \\
\hline UKGS & & & & operasional \\
\hline Kemenkes & & & & \\
\hline
\end{tabular}

2012 .

\section{How}

Kegiatan UKGS di Puskesmas Halmahera meliputi penyuluhan, sikat gigi masal dan penjaringan kesehatan gigi dan mulut yang dilaksanakan hanya satu tahun sekali, yang pada akhirnya berdampak pada tidak tercapainya program UKGS yang ditargetkan kementerian Kesehatan.
Tabel 3. Identifikasi Masalah

\begin{tabular}{lllcl}
\hline \multicolumn{1}{c}{ What } & Where & \multicolumn{1}{c}{ When } & Who & \multicolumn{1}{c}{ Why } \\
\hline Adanya & Di SD & Teridentifikasi & Murid & Kurangnya \\
peningkatan & Karang & dari hasil & kelas & kesadaran \\
jumlah & Tempel & rekapan laporan & selektif & dalam \\
presentase & & UKGS & yaitu kelas pemeliharaan & peman \\
anak yang & & & III dan V & kesehatan gigi \\
mengalami & & & & dan mulut.
\end{tabular}

karies

How

Berdasarkan tabel 3, terlihat kenaikan presentase anak yang mengalami karies dari tahun 2013 ke 2014

Tabel 4. Identifikasi Masalah

\begin{tabular}{|c|c|c|c|c|}
\hline What & Where & When & Who & Why \\
\hline $\begin{array}{l}\text { Belum } \\
\text { terlaksanan } \\
\text { ya UKGS } \\
\text { inovatif }\end{array}$ & $\begin{array}{l}\text { Di SD } \\
\text { Karang } \\
\text { Tempel }\end{array}$ & $\begin{array}{l}\text { Teridentifikasi } \\
\text { oleh Peneliti } \\
\text { selama } \\
\text { melakukan } \\
\text { kegiatan PBL }\end{array}$ & $\begin{array}{l}\text { Murid kelas } \\
\text { selektif yaitu } \\
\text { kelas III dan } \\
\text { V }\end{array}$ & $\begin{array}{lr}\text { Tidak adanya } \\
\text { sarana dan } \\
\text { prasarana yang } \\
\text { mendukung } \\
\text { kegiatan tersebut, } \\
\text { kurangnya } \\
\text { partisipan dari } \\
\text { orang tua. }\end{array}$ \\
\hline
\end{tabular}

Kegiatan penjaringan UKGS yang dilaksanakan di Puskesmas Halmahera belum menerapkan program irine donut.

Tabel 5. Identifikasi Masalah

\begin{tabular}{|c|c|c|c|c|}
\hline What & Where & When & Who & Why \\
\hline $\begin{array}{l}\text { Kurangnya } \\
\text { kelengkapan } \\
\text { data hasil } \\
\text { penjaringan } \\
\text { UKGS }\end{array}$ & $\begin{array}{l}\text { Di SD } \\
\text { wilayah } \\
\text { kerja } \\
\text { Puskesmas } \\
\text { Halmahera }\end{array}$ & $\begin{array}{l}\text { Teridentifikas } \\
\text { i oleh Peneliti } \\
\text { selama } \\
\text { melakukan } \\
\text { kegiatan PBL }\end{array}$ & $\begin{array}{c}\text { Murid SD } \\
\text { wilayah kerja } \\
\text { Puskesmas } \\
\text { Halmahera }\end{array}$ & $\begin{array}{l}\text { Belum adanya } \\
\text { format baku } \\
\text { pemeriksaan } \\
\text { dan pelaporan } \\
\text { kesehatan gigi } \\
\text { dan mulut }\end{array}$ \\
\hline \multicolumn{5}{|c|}{ How } \\
\hline
\end{tabular}

Data hasil pelaporan kegiatan UKGS di Puskesmas Halmahera meliputi karies (IP, HP, PULP, PRD / GR, KG, PT, Crowded, rujuk, sehat dan spesialis).

\section{Prioritas Masalah}

Dalam penetapan prioritas masalah, metode yang digunakan di bidang kesehatan adalah metode Bryant.

Tabel 6. Analisis Prioritas Masalah

\begin{tabular}{|c|c|c|c|c|c|c|c|}
\hline No & Masalah & $\mathbf{C}$ & $\mathbf{P}$ & $\mathbf{S}$ & M & $\begin{array}{c}\text { Total } \\
\text { (CxPxSx } \\
\text { M) } \\
\end{array}$ & $\begin{array}{c}\text { Skala } \\
\text { Periorita } \\
\text { s } \\
\end{array}$ \\
\hline 1 & $\begin{array}{l}\text { Kegiatan UKGS Tahap } \\
\text { III belum merata }\end{array}$ & 2 & 3 & 3 & 3 & 72 & II \\
\hline 2 & $\begin{array}{l}\text { Pelaksanaan } \\
\text { UKGS begiatan } \\
\text { sesuai dengan pedoman } \\
\text { UKGS Kemenkes } 2012 \\
\end{array}$ & 4 & 4 & 4 & 4 & 256 & 1 \\
\hline 3 & $\begin{array}{l}\text { Terjadi peningkatan } \\
\text { angka presentase } \\
\text { penyakit gigi dan mulut } \\
\text { pada tahun } 2013 \text { dan } \\
2014 \text {. }\end{array}$ & 2 & 4 & 4 & 2 & 64 & III \\
\hline 4 & $\begin{array}{l}\text { Belum terlaksananya } \\
\text { UKGS inovatif }\end{array}$ & 1 & 3 & 3 & 3 & 27 & IV \\
\hline 5 & $\begin{array}{l}\text { Kurangnya kelengkapan } \\
\text { data hasil penjaringan } \\
\text { UKGS }\end{array}$ & 1 & 2 & 2 & 4 & 16 & V \\
\hline
\end{tabular}


Berdasarkan hasil perhitungan skor dengan menggunakan metode Bryant, maka Prioritas masalah yang mendapatkan skor terbanyak yaitu "Pelaksanaan Kegiatan UKGS belum optimal”.

\section{Analisa penyebab masalah utama}

Penyebab prioritas masalah dianalisa dengan menggunakan metode $6 \mathrm{M}$ yaitu Man (sumber daya manusia), Money (anggaran dana), Material (sarana), Machine (prasarana), Method (metode/cara), Market (lingkungan).

\begin{tabular}{|c|l|}
\hline Man & $\begin{array}{l}\text { Kurangnya tenaga pelaksana kesehatan gigi } \\
\text { dan mulut dalam kegiatan UKGS } \\
\text { Kurangnya partisipasi orang orang tua dan } \\
\text { motivasi anak dalam perawatan kesehatan } \\
\text { gigi dan mulut lanjutan }\end{array}$ \\
\hline Money & $\begin{array}{l}\text { Kurangnya dana operasional UKGS dari } \\
\text { Dinas Kesehatan Kota Semarang. }\end{array}$ \\
\hline Material & $\begin{array}{l}\text { Belum tersedianya UKGS-Kit dan media } \\
\text { penyuluhan }\end{array}$ \\
\hline Machine & $\begin{array}{l}\text { Beberapa sekolah tidak mempunyai ruang } \\
\text { khusus untuk kegiatan UKS. }\end{array}$ \\
\hline Method & $\begin{array}{l}\text { Tidak adanya pembinaan orang tua, guru, } \\
\text { dan dokter kecil } \\
\text { Tidak adanya upaya perawatan gigi } \\
\text { sederhana di Sekolah } \\
\text { Tidak digunakannya kartu kunjungan ke } \\
\text { Puskesmas } \\
\text { Tidak dilakukan monitoring dan evaluasi } \\
\text { UKGS }\end{array}$ \\
\hline Market & $\begin{array}{l}\text { Dipengaruhi oleh kehidupan sosial } \\
\text { masyarakat }\end{array}$ \\
\hline
\end{tabular}

\section{Alternatif Pemecahan Masalah}

Alternatif pemecahan masalah yang diperoleh dari literatur yang menunjang hasil kegiatan UKGS, diantaranya:

1) Penambahan tenaga kesehatan gigi dan mulut

2) Sosialisasi mengenai pentingnya kesehatan gigi dan mulut kepada orang tua

3) Penambahan pengalokasian dana untuk kegiatan UKGS.

4) Pembaharuan kebijakan kegiatan UKGS sesuai dengan pedoman UKGS Kepmenkes 2012

5) Penerapan program donut Irene menggunakan versi manual
6) Pembaharuan format

pemeriksaan kesehatan gigi dan mulut

7) Penggunaan raport gigi

8) Penggunaan voucher gigi

\section{Alternatif Prioritas Pemecahan Masalah}

Berdasarkan 8 solusi yang ditawarkan penulis, akan diambil satu sebagai prioritasnya dengan menggunakan metode perbandingan efektifitas dan efisiensi.

Tabel 7. Alternatif Prioritas Pemecahan Masalah

\begin{tabular}{|c|c|c|c|c|c|c|c|}
\hline \multirow{2}{*}{ No } & \multirow{2}{*}{ Alternatif Solusi } & \multicolumn{3}{|c|}{ Efektivitas } & \multirow[b]{2}{*}{$\mathrm{E}$} & \multirow{2}{*}{$\begin{array}{c}\sum= \\
(\mathbf{M} \times \mathbf{I} \times \mathbf{v}) \mathrm{E}\end{array}$} & \multirow{2}{*}{ Prioritas } \\
\hline & & $\mathbf{M}$ & I & $\mathbf{V}$ & & & \\
\hline 1 & $\begin{array}{l}\text { Penambahan tenaga } \\
\text { kesehatan gigi dan } \\
\text { mulut }\end{array}$ & 3 & 3 & 2 & 4 & 17 & III \\
\hline 2 & $\begin{array}{l}\text { Sosialisasi mengenai } \\
\text { pentingnya kesehatan } \\
\text { gigi dan mulut } \\
\text { kepada orang tua }\end{array}$ & 2 & 3 & 4 & 2 & 12 & IV \\
\hline 3 & $\begin{array}{l}\text { Penambahan } \\
\text { pengalokasian dana } \\
\text { untuk kegiatan } \\
\text { UKGS serta sarana } \\
\text { dan prasarananya }\end{array}$ & 4 & 3 & 2 & 4 & 6 & V \\
\hline 4 & $\begin{array}{l}\text { Pembaharuan } \\
\text { kebijakan kegiatan } \\
\text { UKGS sesuai dengan } \\
\text { pedoman UKGS } \\
\text { Kepmenkes } 2012\end{array}$ & 5 & 3 & 3 & 1 & 45 & I \\
\hline 5 & $\begin{array}{l}\text { Penerapan program } \\
\text { donut Iren } \\
\text { menggunakan versi } \\
\text { manual }\end{array}$ & 3 & 3 & 4 & 2 & 19 & II \\
\hline 6 & $\begin{array}{l}\text { Keseragaman format } \\
\text { pemeriksaan } \\
\text { kesehatan gigi dan } \\
\text { mulut }\end{array}$ & 2 & 2 & 2 & 2 & 4 & VI \\
\hline 7 & $\begin{array}{l}\text { Penggunaan raport } \\
\text { gigi }\end{array}$ & 2 & 2 & 2 & 3 & 3 & VII \\
\hline 8 & $\begin{array}{l}\text { Penggunaan voucher } \\
\text { gigi }\end{array}$ & 2 & 1 & 2 & 3 & 2 & VIII \\
\hline
\end{tabular}

Berdasarkan hasil perhitungan skor dengan menggunakan metode Perbandingan Efektifitas dan Efisiensi di atas, maka alternatif masalah yang mendapatkan skor terbanyak adalah "Pembaharuan kebijakan kegiatan UKGS sesuai dengan pedoman UKGS Kepmenkes 2012”.

\section{Analisis Prioritas Pemecahan Masalah}

Prioritas Pemecahan masalah yang diperoleh dari tabel alternatif solusi diatas selanjutnya akan dianalisis melalui metode 
SWOT. Metode ini menjabarkan kekuatan (strength), kelemahan (weakness), kesempatan (opportunity) dan ancama (threat) yang dapat muncul sebagai implikasi pelaksanaan prioritas pemecahan masalah.

\section{Kekuatan (strength)}

Pelaksanaan prioritas pemecahan masalah ini memiliki kekuatan atau kelebihan sebagai berikut :

a) Pihak Puskesmas berkewajiban untuk melaksanakan kegiatan UKGS sesuai dengan pedoman.

b) Tersedianya dana tambahan dari pihak terkait.

c) semua murid akan menerima pelayanan kesehatan gigi dan mulut sesuai dengan pedoman UKGS 2012

d) target UKGS bisa tercapai sesuai dengan pedoman UKGS 2012

e) kegiatan UKGS bisa terlaksana secara berkesinambungan

\section{Kelemahan (weakness)}

Kekurangan dari prioritas alternatif pemecahan masalah ini diantaranya :

a) lamanya proses keputusan kebijakan.

b) Butuh dukungan dari berbagai
stokeholder

\section{Kesempatan (opportunity)}

Pelaksanaan prioritas pemecahan masaalah ini dapat menghasilkan kemungkinan yang positif untuk memperbaiki sistem yang ada, diantaranya :

a) mendapat dukungan dari Puskesmas

b) pelaksanaan UKGS dapat meningkatkan derajat kesehatan gigi dan mulut sesuai dengan Keputusan Direktur Jendral Bina Upaya Kesehatan Nomor: HK.02.04/II/963/2012.

\section{Ancaman (threat)}

a) ketidakpedulian petugas puskesmas terhadap adanya kebijakan.

Beragam perbedaan pola pikir setiap individu menjadi salah satu ancaman berjalannya kebijakan tersebut b) kurangnya kesadaran orang tua terhadap kesehatan gigi dan mulut

Metode SWOT di atas menjabarkan apa saja yang dapat terjadi ketika perencanaan dan pelaksanaan prioritas pemecahan masalah ataupun pada saat dan setelah realisasi kegiatan tersebut. Kekurangan dan hambatan yang mungkin timbul hendaknya ditutupi dengan kelebihan yang ada sehingga tidak menimbulkan masalah baru yang lebih serius.

\section{KESIMPULAN}

Laporan kasus ini dapat disimpulkan bahwa kurang optimalnya kegiatan UKGS di Puskesmas Halmahera Semarang dipengaruhi oleh kurangnya tenaga kesehatan gigi, tidak ada dana operasional kegiatan UKGS, tidak adanya monitoring dan evaluasi, dan kurangnya partisipasi dan motivasi orang tua terhadap perawatan gigi lanjutan.

\section{SARAN}

1. Bagi Puskesmas Halmahera

Diharapkan kegiatan UKGS dilaksanakan secara berkesinambungan

2. Bagi Dinas Kesehatan

Diharapkan dapat mengambil langkah yang tepat dalam menentukan kebijakankebijakan sesuai dengan masalah yang ada di Puskesmas.

3. Bagi mahasiswa

Diharapakan dapat memberikan ide-ide dan gagasan guna mengoptimalkan program UKGS

\section{DAFTAR PUSTAKA}

Adiwiryono. (2011). Perilaku Hidup Bersih Dan Sehat (PHBS) Anak Usia Dini Dalam Kurikulum Pendidikan Anak Usia Dini. Surakarta : Universitas

Cahyati, W,H. (2008). Karies Gigi Pada Anak TK. Kemas. vol. 4, no. 1. 
Darwita, R.R. et all., (2006). Keberhasilan Program UKGS dan Peran Guru.http://repository.ui.ac.id/contents /koleksi/2/443bebdb89696fd9cae56da 1592b411735561fb0.pdf.

Novita. U,. A. (2008). Penelitian Kebutuhan Fissure Silent dan Pengalaman Karies Gigi Posterior pada Murid di SDN 2 Medan.

http://library.usu.ac.id/indekx.php/com petent/journal/indekx.php

Prihastari, L. (2014). Tindakan Preventif untuk Kesehatan gigi dan Mulut Rakyat Indonesia. Fakultas Kedokteran Gigi Universitas Indonesia.

Riskesdas. (2013). Laporan Riset Kesehatan Dasar. Badan Penelitian dan Pengembangan Kesehatan Kementerian Kesehatan RI.

Riyanti, E \& Saptarini, R. (2012). Upaya Peningkatan Kesehatan Gigi dan Mulut melalui Perubahan Perilaku Anak. http://pustaka.unpad.ac.id/wpcontent/uploads/2011/09/pustaka_unp ad_Upaya-Peningkatan-KesehatanGigi-dan-Mulut-MelaluiPerubahan.pdf.

Silaban, S. Prevalensi Karies Gigi Geraham Pertama Permanen Pada Anak Umur 8 - 10 Tahun Di SD Kelurahan Kawangkoan Bawah. Kedokteran Gigi Fakultas Kedokteran Universitas Sam Ratulangi.

Survey Kesehatan Rumah Tangga (2001). Badan Penelitian dan pengembangan Kesehatan. Departemen Kesehatan Republik Indonesia. 